\title{
Transparency and insurance professionals: a study of Swedish insurance practice attitudes and future development
}

\author{
Jacob Dexe ${ }^{1}$ (D) Ulrik Franke $^{1} \cdot$ Alexander Rad $^{1}$
}

Received: 26 May 2020 / Accepted: 26 January 2021 / Published online: 4 March 2021

(c) The Geneva Association 2021

\begin{abstract}
The insurance industry is being challenged by increased adoption of automated decision-making. AI advances could conceivably automate everything: marketing, customer service, underwriting and claims management alike. However, such automation challenges consumer trust, as there is considerable public and scholarly debate over the 'black box' character of many algorithms. Insurance being a business of trust, this suggests a dilemma. One suggested solution involves adopting algorithms in a transparent manner. This article reports a study of how Swedish insurers deal with this dilemma, based on (i) eight interviews with insurance professionals representing four companies with a joint market share of $45-50 \%$ of the Swedish property insurance market and (ii) a questionnaire answered by 71 professionals in a Swedish insurance company. The results show that while transparency is seen as potentially valuable, most Swedish insurers do not use it to gain a competitive advantage or identify clear limits to transparency and are not using AI extensively.
\end{abstract}

Keywords Transparency · Openness · Trust · Insurance $\cdot$ Competitive advantage . Sweden

Jacob Dexe

jacob.dexe@ri.se

Ulrik Franke

ulrik.franke@ri.se

Alexander Rad

alexander.rad@ri.se

1 RISE Research Institutes of Sweden, P.O. Box 1263, 16429 Kista, Sweden 


\section{Introduction}

The insurance industry faces challenges. According to an analysis by The Economist, "insurers face unprecedented competitive pressure owing to technological change" (The Economist 2017). The reason is simple: few substitutes to the product, steady flows of investment revenue and large customer bases have worked well. Until now, that is, when advances in automated decision-making suddenly offer the prospects of automating everything: marketing, customer service, underwriting and claims management.

In an analysis by Insurance Sweden, a Swedish industry organisation, the impact of digitalisation through the entire value chain is discussed (Insurance Sweden 2016, 117-119). For product design, it is foreseen that greater availability of data will enable more personalised insurance products. In underwriting, telematics is expected to feed real-time data about the status of cars, homes and individuals, enabling more precise pricing. Digital distribution is increasingly becoming the norm in property insurance, with customers expecting sales through digital channels that are easy to use, personalised and understandable. Finally, some claims adjustments could become fully automated, being filed online, algorithmically inspected and paid out. Insurance Sweden thus predicts that new data and analytics will enable a refocusing from reactive payouts to proactive prevention. Either the established players of the industry will increasingly adopt the technology to automate their core business or technology-based startup challengers like the U.S. company Lemonade (Klingler 2018; Riikkinen et al. 2018) will do it instead. Or so the argument goes.

However, while there is undoubtedly much value to be unlocked from the increasing use of modern technology by insurers, there is also reason to be cautious. Insurance is a 'trust management business' (van Rossum 2004). As opposed to tangible goods that can be seen and inspected when bought, insurance is not possible without trust-in solvency, profitability and governance (de Castries 2004). Such trust matters not only to consumers, but also to underwriters and brokers (Zboron 2015), and cannot be taken for granted; there is some evidence that consumers distrust companies in general (Adams et al. 2010).

This suggests a potential dilemma: the increasing use of automated decisionmaking might lead to decreased trust. The reason is that even though recent advances in artificial intelligence (AI) have led to impressive results, many algorithms are obscure and 'black box'-like (Castelvecchi 2016). Whereas with traditional programming it is at least possible to read the code in order to figure out what it does, the novel machine learning systems learn from data in a way that seldom lends itself well to explanation. Thus, the public debate is full of concern about the various forms of bias in automated decision-making that have been discovered, disadvantaging, for example, poorer people and those from minorities (Nature 2016). A further complicating factor is that the data collection needed to fuel algorithms can also be controversial. Though the exact worth of consumer data is context-dependent and disputed (Kugler 2018; Spiekermann and Korunovska 2017), it is clear that such data is at the heart of many digital business 
models. 'Data is the new oil', as the saying goes. However, research indicates that consumers "are deeply anxious about how their personal information may be used" (Morey et al. 2015, 4). The insurance industry in particular has received its share of this criticism, both in terms of opaque models and intrusive data collection (O’Neil 2016).

While there might be no single panacea that resolves this dilemma once and for all, one strategy - or rather a set of related strategies - that has been suggested is transparency about decision-support models, data collection, etc. It has been argued that such transparency can indeed be used to foster trust among insurance customers (Atchinson 2004) and possibly also endow a competitive advantage in the face of 'unprecedented competitive pressure' (The Economist 2017).

It is against this background that the overall research question of this article was conceived: Do Swedish insurance companies use transparency and openness to gain increased trust? More precisely, the following research questions (RQs) are addressed:

RQ1 How do Swedish insurance companies view transparency and openness with respect to potential competitive advantage?

RQ2 Do Swedish insurance companies use transparency and openness as strategic tools?

RQ3 Which limits to transparency and openness do Swedish insurance companies identify?

RQ4 Do Swedish insurance companies use AI technology, and how do they reason about its relation to trust?

The remainder of the paper is structured as follows: the next section introduces some related work on trust, transparency and insurance and the subsequent section discusses some relevant preparatory work on consumer attitudes to transparency. The Methodology section explains the data collection methods used. The findings are first described in the Results section, then discussed in the Discussion section. The final section concludes and offers some directions for future work.

\section{Related work}

There is a large body of literature on the relationship between trust and transparency, often related to macroscopic social science questions such as corruption (Park and Blenkinsopp 2011) and citizen empowerment (Kim and Lee 2012). A recent comprehensive review of trust and transparency in government is given by Cucciniello et al. (2017). In the following, we instead review three somewhat more delimited areas of the trust and transparency literature, viz. customer relations, AI and insurance, respectively. 


\section{Trust and transparency in customer relations}

Kang and Hustvedt (2014) investigate consumer perception of efforts to be transparent and socially responsible. Analysing 909 responses (303 respondents reflecting on three companies) they show that transparency and social responsibility have a significant effect on trust and general attitude towards a company, as well as on word-of-mouth and purchase intention, with transparency having a larger effect size than social responsibility. Trust may also be a more important factor than general attitude in predicting consumer intention and is thus the value companies ought to prioritise.

Bhaduri and Ha-Brookshire (2011) tried to understand consumer attitude and purchase intention based on transparency in supply chains. Thirteen interviews revealed that strong values associated with responsible purchasing increased the value of transparency, but there was also a general distrust towards the legitimacy of claims regarding transparency. The study suggests that transparency creates stronger positive associations if the consumer is somewhat passionate about making 'correct' choices.

Similarly, Cambier and Poncin (2020) show brand integrity (which includes trustworthiness) can be boosted by transparency signalling through advertising. Perceived empowerment seems to mediate the effect of transparency, and transparency signalling may boost brand integrity more for companies with poor reputation. Kim and Kim (2017) instead show that transparency in the hotel industry has a moderating effect on the relation between corporate social responsibility and corporate ability on one hand, and customer satisfaction and trust on the other.

\section{Trust and transparency related to Al}

This is not the place for an in-depth discussion of the technical details of explainable AI, but reviews include Guidotti et al. (2018) and Du et al. (2019). Briefly stated, the technically-oriented literature is for the most part concerned with techniques that can be used to convert less explainable models such as (deep) neural networks or support vector machines into more explainable ones such as decision trees (Andrews et al. 1995; Barakat and Bradley 2010) or heat and salience maps (Samek et al. 2016; Adebayo et al. 2018). Increased explainability in these models comes at a cost-they typically only explain the local behaviour of a small part of the original model, or perform worse (in terms of standard measures such as precision and recall) than the original model.

To rectify problems of automated decision-making with limited transparency and explainability, Fleischmann and Wallace (2005) argue that designers of all models used for decision support should work hard to make these as transparent as possible, because in the absence of transparency, end-users cannot make informed decisions. More broadly, it is typically held that there are no simple and purely technological answers to these issues, but that 'holistic, multi-disciplinary, and multi-stakeholder' approaches (Rossi 2018, 132) ranging from 
individual systems and applications (such as insurance) to the institutional level (Winfield and Jirotka 2018) are needed. As pointed out by Coeckelbergh (2019), explainability is not just a matter of the creators of AI models knowing what they are doing (as moral agents), but also a matter of those affected by AI (i.e. all of us as moral patients) being entitled to reasons for actions and decisions made by AI. In that vein, Siau and Wang (2018) examine how trust in AI may be different from trust in other technologies based on its enhanced capabilities in comparison to other technologies. The lesson from this is that it is important to think of representations, trials, ease of use, reliability and a myriad of other perspectives, as well as managing negative perceptions (i.e. a representation of an AI as a robot pet will facilitate trust, while the Terminator will hinder trust).

Taking a closer look at some strands of the literature, de Laat (2018) dissects the argument that transparency can create accountability for machine learning systems, identifying several objections to full transparency: (i) loss of privacy, (ii) perverse effects ('gaming the system'), (iii) loss of competitive edge and (iv) limited gains since, as noted above, increased explainability comes at a cost. On balance, de Laat argues that only oversight bodies, not the public at large, should be entitled to full transparency.

Zerilli et al. (2019) point out that, while much of the debate focuses on the shortcomings of machine decision-making, human decision-making also has its share of transparency problems. Thus, while transparency and explainability are important for humans as well as for machines, Zerilli et al. worry that machines are held to unrealistically high standards, based on an unrealistic conception of humans. They argue for more nuanced transparency requirements and give some directions for what those might look like, based on intentional stance theory (Dennett 1989). Departing from the same observation about lack of transparency in human decision-making, Wischmeyer (2020) argues it is easier than often assumed to design good AI transparency regulation, since the legal system is already accustomed to dealing with partially opaque human decision-making. Another interesting line of reasoning comes from Turilli and Floridi (2009), who argue that transparency is not an ethical principle in itself, but rather a pro-ethical condition that can enable ethical principles related to, for example, accountability, informed consent and safety.

An interesting experiment on the effect of transparency on trust was carried out by Kizilcec (2016), who tested three levels of system transparency in a grading context. Interestingly, subjects whose expectations were met trusted the system equally, regardless of transparency, but subjects whose expectations were not met required more transparency to reach the same level of trust. Another experiment is reported by Lakkaraju and Bastani (2020). Since even good explanations of AI systems do not necessarily reflect biases, explanations can actually be misleading and foster unwarranted human trust. Lakkaraju and Bastani conducted a user study, empirically establishing that such undeserved trust can be established. Such results underline the importance of not only considering the explainability problem from a strict computer science perspective, but also considering human-computer interaction (HCI) aspects (Abdul et al. 2018). 


\section{Trust and transparency in insurance}

The scholarly work on trust and transparency in insurance covers several different areas:

The multitude of relationships in which transparency is relevant is discussed by van der Sluijs (2019). She distinguishes transparency (i) between insurers and intermediaries on the one hand and their customers on the other hand and (ii) between insurers and intermediaries on the one hand and supervisory authorities on the other hand. Van Rossum (2004) also touches upon this multitude of relationships, adding transparency (iii) between an insurer and its shareholders, especially minority and foreign shareholders, as well as (iv) between an insurer and its audit committee.

Transparency in compensation schemes is an area that insurance shares with the wider financial industry. For example, Lynch (2009) argues informally that financial advisors should disclose how their compensation is earned (e.g. through commissions, hourly fees, etc.), and that doing so will enhance customer trust. Focht et al. (2013) discuss broker compensation issues using a formal model and find that, while the existence of brokers as such increase transparency and thus competition, to the benefit of insurance customers, it is questionable whether transparency in the compensation to these brokers would impact on advice quality. In a rare empirical investigation, Cupach and Carson (2002) test whether different forms of compensation influence insurance agent recommendations of products, finding no such effect. In the context of brokers, it is also noteworthy that the EU Insurance Distribution Directive establishes transparency as a guiding principle for the entire distribution process precisely in order to make brokers more trustworthy in the eyes of their customers (Malinowska 2016; Köhne and Brömmelmeyer 2018).

Transparency in investments and financial reporting are also areas shared with the wider financial industry. Scott (2004), in the wake of the Enron scandal, argues that the insurance industry is actually in a position to lead by example and that by adopting a 'spirit of transparency' it could influence other stakeholders in a positive direction. For more thorough reviews of financial reporting regulations in general see Bushman and Landsman (2010), and of the impact of the Fair Value financial reporting on insurance companies in particular see Dickinson and Liedtke (2004).

de Castries (2004) makes an interesting observation about transparency and complexity of particular relevance to consumers. Rhetorically, he asks whether you need to know and understand all the elements of your car to drive it effectively, of if you just need to know the basics and have a good mechanic when things go wrong? Thus, he also draws attention to the limits of transparency-it is not just that more is better, but its use is contextual. An empirical investigation into transparency practices in insurance is carried out by Dexe et al. (2020), showing different interpretations of how to present information on home insurance to consumers. 
Would you consider changing from one digital service to another if the new service is more open and transparent with how they use your personal information? E.g. a streaming service, internet bank, medical app, etc.

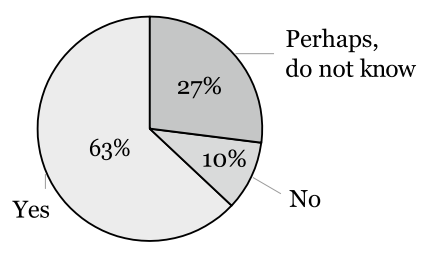

Would you consider changing even if the new service is more expensive?

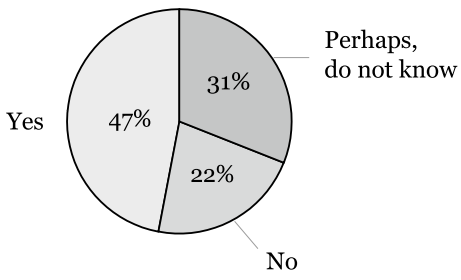

Fig. 1 Consumer attitudes on openness and transparency (Delade Meningar 2019), translation from Swedish, used as introductory material for the interviews

\section{Summary of related work}

While it is clear that the issues of trust and transparency have attracted much attention in the literature, the more delimited questions of how insurance companies can use transparency and openness to gain increased trust from customers is much less treated. While there are many studies of how transparency affects consumer perception, including purchasing decisions (Kang and Hustvedt 2014; Bhaduri and HaBrookshire 2011; Cambier and Poncin 2020), these questions have not been as frequently investigated in the insurance business. While more normative arguments for transparency have been made (Atchinson 2004; Scott 2004), empirical investigations of actual strategic practices have not been found, especially not in the modern AI context that permeates the research presented in the next section. Thus, this paper makes a novel contribution to the state of knowledge in this area, at the intersection of corporate strategy, transparency, insurance and AI.

\section{Data on consumer attitudes}

While the main part of this investigation deals with the supply side, i.e. insurance companies, some preparatory work was also carried out with the demand side, i.e. consumers. ${ }^{1}$ In the 2019 version of the opinion poll Delade Meningar (separately published as a technical report in Delade Meningar 2019), it was decided to include a question on attitudes to openness and transparency in digital services. This was deliberately done to obtain a consumer-oriented contrast to the planned future

\footnotetext{
${ }_{1}$ More precisely, the first author has for several years participated in the design of a series of consumer opinion polls called Delade Meningar, covering the topic digital privacy, carried out by a consortium of private, public and academic stakeholders since 2015 .
} 
Transparency and openness here mean to act in such a way as to allow others to see what you do. It could be information accessible to customers about which data are used, how they are used, who has access to them and which terms of service apply. It could be information that is presented on a website, that is made available if asked for, or that is actively given to customers. There is an idealised view that more transparency is always better than less, but we also know that there are clear limits to what could and should be open.

Fig. 2 Tentative definition of transparency and openness, translation from Swedish, used as introductory material for the interviews

supply-side research. The openness and transparency question, along with the rest of the questionnaire, was posed to a web panel of 1000 Swedes aged 16 to 70 years in January 2019. The answers are depicted in Fig. 1.

As can be seen, a substantial majority would consider changing to a more transparent and open digital service when asked about this simpliciter. However, since it is well known that stated and revealed preferences often diverge, a follow-up question was posed to those (63\%) that answered affirmatively: would they still consider changing even if the new service was more expensive? Unsurprisingly, many then reconsider. However, $47 \%$ still answer affirmatively, thus indicating that some $30 \%$ of Swedish consumers claim to be willing to pay for increased transparency and openness in digital services. Again, it must be stressed that this willingness to pay cannot be taken at face value. Revealed preferences are likely to be different, and consumer behaviour may also differ across different services. Indeed, insurance was not mentioned among the examples given. Nevertheless, these consumer attitudes pose an interesting and thought-provoking starting point for discussing strategic issues related to transparency and openness, as described in the following.

\section{Methodology}

The method used is twofold: data were collected (i) through semi-structured interviews with experts in insurance companies active on the Swedish market and (ii) through a questionnaire distributed to insurance professionals at one of the biggest Swedish insurance companies who had just taken the Elements of AI course. ${ }^{2}$ In the following, these two modes of data collection are detailed in the sections Interviews with insurance experts and Insurance professional questionnaire, respectively.

\section{Interviews with insurance experts}

Interview questions for a semi-structured interview were iteratively put together by the authors. After a first iteration, the overall research question and methodology

\footnotetext{
${ }^{2}$ https://www.elementsofai.com
}

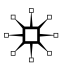


1. Do you believe that transparency or openness (about, e.g., marketing, pricing, policy conditions, claims management) can be a competitive advantage?

- In what way? What effects will it have?

- What if you take technological development into account?

2. What information, in your opinion, is reasonable to be transparent about?

- Does ease of access play a role?

3. Do you conduct any market research on your customers' opinions about transparency?

4. Do you believe that you are more or less transparent than your average competitors today?

- Is there any competitor that is doing better? Or at least doing good?

5. Should theinsurance industry adopt common guidelines for transparency? (As, e.g., Swiss researchers have done preparatory work on)

6. Do you believe that you yourself have complete, or sufficient, information about your products?

7. Is there any policy about how much information customers should have access to?

- Does this still apply when taking technological development into account?

8. Is there any information that customers should or could not have access to?

Fig. 3 Interview guide for semi-structured interviews with insurance experts, translation from Swedish

were discussed with the insurance company funding this research. Their input spawned a second iteration. The list of questions thus obtained was also complemented with the introductory material shown in Fig. 1 and tested in a role play, where one of the authors played the informant and the other two conducted the interview. Based on this experience, one question was removed and two more questions were added to the interview guide. Furthermore, it was decided to add a tentative definition of transparency and openness to the background material, as seen in Fig. 2. The final set of interview questions is shown in Fig. 3. The interviews ranged in time from 40 to $54 \mathrm{~min}$, with an average of $47 \mathrm{~min}$ and $20 \mathrm{~s}$.

Interviews were conducted with experts in Swedish insurance companies. The respondents all have managerial roles, ranging from middle managers (7) to upper management (1). The eight informants representing four companies were interviewed in the fall of 2019 and spring of 2020. Selection was carried out by approaching various consumer-facing insurance companies on the Swedish market. As the research questions concern strategic issues, it was foreseen that a number of companies would decline to participate. The four companies together represent an approximate market share of $45-50 \%$ of the Swedish property insurance market. ${ }^{3}$

The interviews aimed to cover two distinct roles within the companies: (i) customer relations \& operations and (ii) product development. Informants were thus able to give complementary answers, painting a richer picture of each company than

\footnotetext{
3 These figures are based on the official market statistics of Q4 2019 from Insurance Sweden (https:// www.svenskforsakring.se/globalassets/statistik/forsakringsmarknaden/forsakringsmarknaden-2019k 4.pdf, diagram 6).
} 
- Doyou believe that transparency and openness in AI decision-making can be a competitive advantage for Länsförsäkringar?
$\square$ Yes
$\square$ No
$\square$ Uncertain
$\square$ Do not know

- In what way? Please elaborate your answer!

Fig. 4 Questionnaire distributed to insurance professionals who had just taken the Elements of AI course, translation from Swedish

if just single respondents had been approached. In the following, individual informants are coded as CXRY for representative $\mathrm{Y}$ of company X, e.g. C2R3 being the third representative of the second company.

Seven interviews were conducted by two of the authors, one was conducted by only one. The 2019 interviews were conducted as physical meetings at company offices, but due to the outbreak of the COVID-19 pandemic, all the 2020 interviews were instead conducted as teleconferences (audio and video). All interviews were recorded, with the consent of the interviewee, and subsequently transcribed before analysis.

The interviews were analysed through an iterative process. The main author participated in all interviews and noted down themes during and closely after each respective interview, creating a first suggestion for how to process the interviews. During transcription, the author highlighted noteworthy statements and arguments, again iterating the themes based on a second, more thorough, reading of the interviews, creating a detailed list of topics and themes. Finally, the transcribed interviews were analysed and quotes were fitted to the various themes, and a final iteration of the content of the interviews was done in collaboration with the other authors.

Given RQ4, it is worth commenting on the fact that AI does not feature explicitly in Fig. 3. Despite the absence of a dedicated question, most of the interviews dealt heavily with AI and machine learning technologies when discussing future developments for transparency in insurance. In the few interviews where the respondent did not independently discuss AI and machine learning, the authors asked explicit AIrelated questions to get respondents to consider the issue. Thus, it was ascertained that AI questions featured in all interviews.

\section{Questionnaire to insurance professionals}

As a complement to the 'narrow' supply-side investigation with a handful of indepth interviews, a 'broad' supply-side investigation was carried out by a questionnaire to 200 insurance professionals who had just taken the Elements of AI course as part of an initiative by their employer, Länsförsäkringar, one of the largest Swedish insurance companies, the research foundation of which also funded this research. As this population of informants represent people knowledgeable in both insurance and AI, their opinions on openness and transparency were deemed valuable, able to shed light on the RQs. 
Fig. 5 Do you believe that transparency and openness in AI decision-making can be a competitive advantage for Länsforsäkringar?

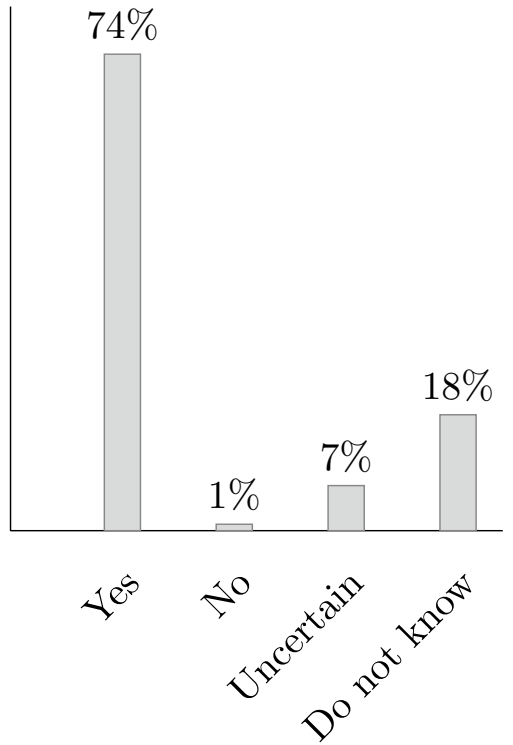

Data collection was carried out in conjunction with course completion and evaluation in April/May 2020. To complement the interview-based data collection, it was deliberately decided to keep the questionnaire very short. Thus, based on the interview questions in Fig. 3, the questionnaire shown in Fig. 4 was developed and distributed to the respondents. In all, 71 answers were received, corresponding to a response rate of $35 \%$. In addition, the respondents were allowed to expand on their answer in a free text box. Unfortunately none of the participants chose to do so.

\section{Results}

\section{Questionnaire}

The results from the questionnaire are depicted in Fig. 5. It is clear that there is very little skepticism about the potential of openness and transparency-only a single respondent answered the question in the negative, while $74 \%$ answered in the positive. However, it is also clear that there is much uncertainty about the potential benefits, as $7 \%$ answer that they are uncertain and $18 \%$ confess their ignorance.

Thus, without giving definitive answers, the questionnaire confirms the relevance of the broader topic, as investigated in more depth in the interviews to which we now turn. 
Table 1 Summary of interview respondent characteristics

\begin{tabular}{llllll}
\hline Respondent & $\begin{array}{l}\text { Customer relations } \\
\text { and operations }\end{array}$ & $\begin{array}{l}\text { Product devel- } \\
\text { opment }\end{array}$ & Motor & Health & Management level \\
\hline C1R1 & $\mathrm{X}$ & $\mathrm{X}$ & & Middle \\
$\mathrm{C} 1 \mathrm{R} 2$ & & $\mathrm{X}$ & $\mathrm{X}$ & & Middle \\
$\mathrm{C} 2 \mathrm{R} 1$ & $\mathrm{X}$ & $\mathrm{X}$ & & Middle \\
$\mathrm{C} 2 \mathrm{R} 2$ & $\mathrm{X}$ & $\mathrm{X}$ & & $\mathrm{X}$ & Middle \\
$\mathrm{C} 2 \mathrm{R} 3$ & $\mathrm{X}$ & $\mathrm{X}$ & & Middle \\
C3R1 & $\mathrm{X}$ & $\mathrm{X}$ & & Middle \\
C3R2 & & $\mathrm{X}$ & & Upper \\
C4R1 & & & & & Middle \\
\hline
\end{tabular}

\section{Interviews}

In Table 1, an overview of respondent characteristics is given. As seen, the eight respondents from companies $\mathrm{C} 1-\mathrm{C} 4$ offer a number of complementary perspectives, with representatives from both customer relations and operations and product development, from both motor and health insurance products as well as some generalists, and from both middle and upper management.

Throughout the interviews, four overarching themes were identified: the value of transparency, the limits of transparency, understandability as a criterion for transparency and how technology and opinion affect transparency.

\section{The value of transparency}

A common perceived value of transparency among the experts is trust building (C1R1, C3R1). On this note, two explicitly mention the 'insurance is in the business of trust' dictum (C2R1, C4R1) while C3R2 alludes to it by saying "If you're selling safeness ${ }^{4}$ you need to be open and transparent with what you're actually selling". This fits with the findings of Kang and Hustvedt (2014) that transparency indeed does impact trust, general attitude, word-of-mouth intention and purchase intention.

There is a 'myth' (C3R2) that insurance companies are hiding behind complicated legalese to avoid fulfilling perceived commitments. C2R2 notes that expectation management has historically been lacking, leading to clients leaving when premiums changed - not necessarily because the premiums are unreasonable, but because they have not been properly motivated. C3R2 points out that factors that make models hard to explain should perhaps not be made explicit to customer relations workers, as transparency would decrease rather than increase understandability.

\footnotetext{
4 The Swedish word 'Trygghet' is hard to translate directly into English. It is commonly translated as security or safety, but as it is also tied to trust, well-being and comfort and is more accurately translated as safeness.
} 
Another value is transparency as a precondition for decision-making, by the mechanism that transparent pricing offers incentives that change behaviour (C2R1). Customers could then use insurance as a means of rational self-control.

In business-to-business (B2B) insurance (C2R2), transparency was identified as something of a hygiene factor. With a large customer, it is not possible, for example, to impose sudden changes in premium rates at annual renewal, but the account has to be transparently managed over time.

Another informant (C1R2) identifies lack of transparency in most B2C offerings as an opportunity for start-ups to upend the industry, claiming that consumers typically do not know what they pay for, how the claims process looks, how long they will need to wait on the phone, etc.

The opposing view was also voiced by one informant (C2R3), who argued that transparency is vastly outweighed by other factors, such as price, coverage and brand credibility, a sentiment mirrored in other interviews (C2R1, C4R1). C2R3 did acknowledge, though, that there could be consumer groups who are attracted by transparency, on the margin, so that it could prove a competitive advantage with respect to them. This is in line with the findings of Bhaduri and Ha-Brookshire (2011) that transparency is important to customers who care about responsible purchasing.

Another position on transparency is that there is nothing to hide from competitors because the business models-on particular lines, in contrast to other lines where this is not the case-are all so similar anyway (C2R1). Thus, there is nothing to gain from not being transparent. Another informant (C2R3) takes the same position, but with respect to customers rather than competitors: the insurance product $\mathrm{C} 2 \mathrm{R} 3 \mathrm{man}-$ ages has very simple pricing and the respondent would feel perfectly comfortable answering any pricing question at all.

Finally, transparency was also mentioned as a value in intraorganisational processes (C1R1).

\section{Limits to transparency}

Throughout the interviews, respondents either explicitly or implicitly touched on aspects of their respective operations that were not transparent or where transparency was somehow lacking, both as a reflection on the state of current practices, as well as normative statements on the limitations of transparency.

Some informants stress that transparency is their default position (C1R2) and that the limits mostly arise from laws, foremost the GDPR, on personally identifiable information (PII) (C1R1, C2R1). Indeed, one of these informants persists with the transparent position even when asked explicitly about showing actuarial models to competitors 
(C1R1). The concern about privacy and PII is familiar from the literature: consumers are aware that they are under surveillance and are anxious about it (Morey et al. 2015). This is also known to be the case in Sweden (Delade Meningar 2018, 2019). C3R2 expands on this point, arguing that even though people seem to like the increased transparency of smart car insurance, very few make the choice to use it "because they feel like they're being surveilled". 5

Indeed, transparency about use of personal data was highlighted by several respondents: "if we collect information, we are open about that" (C2R1), a sentiment echoed by C3R2 and C4R1. Closely tied to what particular personal data is being used is for which purposes that data is used (C4R1). The practical limitations of such transparency in insurance are discussed further in Dexe et al. (2020).

While some respondents are open to letting pricing be fully transparent, most were adamant that pricing is an area where transparency is lacking and there are reasons for it to stay that way. Information about what the price is based on (C2R3, C3R2) as well as what the business model looks like in general (C1R2). In contrast with the nothing to hide with competetitors position in the previous section, there is the position that business secrets impose limits on transparency (C2R2, C4R1). Notably, these two perspectives are not contradictory per se - they can simply apply to different business areas.

There might even have to be limits on offering open quotes online (so as to make it harder to figure out price models, C2R3). C4R1 also mentions that most complaints about price do not stem from the customer thinking that the price is too high, but rather that the customer considers herself a better risk than the price shows - and demanding that the company recognises the actual risk of the individual. C4R1 continues this line of reasoning to state that having fully individualised (and transparent) pricing will lead to the entire concept of shared risk in insurance being undermined.

A reason for not being transparent is that complicated policies and wording risks imposing an additional burden on the customer (C2R1, C3R2, C4R1). This reminds of one of the remarks from de Castries (2004) about what you need to know about your car. A similar idea is discussed by C3R2, who says that, in light of the amount of parameters the company works with and could theoretically be transparent with, "If you're transparent with pricing, people will feel like they're being followed", a statement reminiscent of de Laat (2018).

Finally, some respondents also noted that sometimes there should be no limits to transparency. C3R2 mentions that companies ought to be open about all types of general information to the consumer, but in a condensed manner-and later stating that on the product side of things everything could be transparent, "perhaps extremely transparent". In the context of a specific insurance being fairly rudimentary, C2R3 states that "it should be completely see through. I can't see any problem with that whatsoever". To the question "What is reasonable to be transparent with?" C1R1 simply says "Everything!".

\footnotetext{
5 Smart car insurance is used here to describe a type of insurance where hardware is installed in the car and the insurance company evaluates how 'safe' the insurance holder's driving is by looking at acceleration, breaking patterns, geographic position, time and so on. 'Safe' driving can lead to reduced premiums, while unsafe conduct currently only leads to the customer paying a base rate instead of a reduced rate.
} 


\section{Making information understandable}

Presenting information in pedagogical ways may do more towards increasing understanding than simply having the information available. In the following section, the experts discuss understandability as a factor in transparency.

Creating the "best insurance experience" (C1R1) means trying to design information so that you create understanding without overloading the users with information (C1R1, C2R1). It can be done through dialogue (C2R2) or through user experience design $(\mathrm{C} 1 \mathrm{R} 1)$ and the common theme seems to be making sure that language is accessible (C1R1, C2R1).

A complicating factor is that terms and conditions are inherently hard to understand, but have to be read in order for the consumer to be able to make an active choice (C1R1, C2R1). It's also a matter of actually getting consumers to read the information, because transparency doesn't matter if the information is incomprehensible: "We could write a bunch of super easy, nice, conditions that everyone can understand, but if they don't read them we can't set proper expectations" (C1R1), a sentiment echoed by C1R2, C2R 2 and C3R2.

It is interesting to consider these responses in light of the literature showing that brand integrity (including trustworthiness) can be boosted by transparency signalling through advertising (Cambier and Poncin 2020).

Transparency about terms and conditions was discussed in all interviews. Some respondents reasoned that in one sense their companies are transparent because terms and conditions are available for everyone (C2R1, C3R2, C4R1) while others argued that terms and conditions are not transparent despite them being available (C1R1, C1R2): terms and conditions "are written in a very difficult language. It's a part of transparency to write in an accessible way" (C1R1). This is reminiscent of Atchinson (2004), who argues the importance of letting consumers understand policies. However, several respondents point to the terms and conditions and other legal documents as something they do not consider to be transparent, due to the problem of understanding the legal language (C1R2, C3R2) and the quantity of information (C2R1). In reference to the latter, the respondent characterises it by saying "You can't see the forest for the trees".

The point of contention with terms and conditions may come down to a matter of communication, presenting the information in a way that customers may actually comprehend. C1R1 says that with a lack of attention to pedagogy, customers may not understand the insurance and will assume protection where there is none.

Finally, other aspects of understandability include the application of transparency in explaining the effects of using data (C1R2), as a marketing device (C2R3) (compare Cambier and Poncin 2020), and in terms of showing code rather than data (C1R1).

Transparency with the process of insurance was another aspect mentioned by most respondents. In particular, respondents from $\mathrm{C} 1$ were vocal about the need to show customers where in the process they currently are (be it claims, sales or any matter of customer support) and handling their questions without delays. $\mathrm{C} 1$ representatives talked about this kind of transparency as accessibility explicitly, 
as did C2R2. The other companies dealt with customer support expediency more indirectly.

Respondents also emphasised that transparency can be a tool for expectation management, mentioning transparency with conditions (C1R1, C2R1, C3R2) in order to build the right expectations, meeting those expectations (C1R2) and being transparent with what is not included and risks identified (C3R2). C3R2 states that "it could prevent damages if we're clear with what risks exist and how large they are. A lot of people are afraid of burglaries, but as a home owner it's more reasonable to be afraid of water leakage". It is interesting to consider this in light of the result from Kizilcec (2016); people whose expectations are met require less explanation to obtain a given level of trust than those whose expectations are not met.

A specific part of expectation management is transparency about pricing, where the perceived customer value is framed and anchored by previous experiences. C1R1 and C1R2 both argued for transparency in pricing, while C2R1 claimed that $\mathrm{C} 2$ was the most transparent with pricing on the market. As reported in the previous section, however, several respondents also argued against pricing transparency.

\section{Shifting attitudes and $\mathrm{Al}$}

Throughout the interviews, respondents reflected on the future of transparency in insurance. These reflections were partly motivated by shifting consumer attitudes and partly by technological developments such as artificial intelligence.

Consumer attitudes will continue to evolve, but the direction is not clear: "What does the younger generation think in 10 years? I don't dare to answer that."(C3R2). While one respondent dismisses consumer demand for transparency today (C2R3), another says that the pendulum might swing from high consumer demand today toward less in the future (C2R1). Others see demand for transparency increasing in the future (C2R2, C3R2).

Considering technological development, respondents highlighted the wellknown problem of explanations in automated decisions (Guidotti et al. 2018; Du et al. 2019). To exemplify: "If we knew what the price was based on five years ago, we know a lot less today when using machine learning" (C3R2). Some did, however, point to this being a theoretical rather than a practical problem, due to the lack of implementation of AI solutions in the current insurance market (C1R1, C2R1, C2R3).

C2R3 likened the use of technology to a force of nature, where companies will 'over-use' the solutions. C1R1 wavered on the balance between explainability and the efficiency of AI systems, eventually coming to the conclusion that, in the end, it would be preferable to use explainable technologies to the furthest possible extent. This is in line with the position advocated by Fleischmann and Wallace (2005). C2R2 was one of many who pointed out that the use of new technologies based on new kinds of data will also require the requisite consent, much in line with the reasoning of, for example, Morey et al. (2015).

With increased use of data, not only in AI systems, one respondent also identifies a potential future risk where the combination of individual risk assessment and 
transparency leads to adverse selection-as people get to know their risk scores, only those with high risk scores will find it worthwhile to insure themselves (C2R3).

\section{Discussion}

In line with the diversity of the literature, the interviews reveal a plethora of transparency aspects: expectation management, pricing information, demands on operations (legal or otherwise), relationships with competitors, relationships with individuals and AI and future-proofing transparency. These aspects are discussed in the following subsections, before a concluding discussion of validity and reliability.

All interviews were centered on the first relationship in van der Sluijs (2019), the transparency between the insurer and their customers, and only a small part focused on the second relationship, between insurers and supervisory authorities, and then pretty much only in terms of data protection. None of the respondents mentioned the third or fourth relationship that van Rossum (2004) expanded on. This is likely partly due to framing through the initial contacts, where the authors gave a consumer-oriented introduction to the topic.

\section{Expectation management}

Throughout the entire previous section, the most common transparency relationship discussed was how insurance companies try to set customer expectations-by presenting information in an understandable way and by what information is conveyed-with terms and conditions being the main type. The interviews discussed the value of transparency in line with Atchinson (2004), arguing that it is important to let consumers understand policies and explain reasons, while also acknowledging the limitations regarding complexity highlighted by de Castries (2004).

Trust was the most frequently discussed value that could be fulfilled through transparency. The self-imposed dictum of 'insurance is in the business of trust' does indeed seem to resonate with the experts. Trust is linked to expectation management (as well as some other aspects in this chapter) in that trusting a company means that you assume that the expectations you have will be met. Setting expectations, and living up to those expectations, is a way to earn trust, and transparency is key in that process (Kang and Hustvedt 2014).

Interestingly, in The value of transparency section, we see a divergence in what values respondents see. While $\mathrm{C} 2 \mathrm{R} 2$ highlights transparency as a hygiene factor in B2B insurance sales, others argue that consumers might not care about transparency or may prioritise other values. Turilli and Floridi (2009) argue that transparency is not necessarily a good in and of itself, but can rather be used to achieve other values, labelling transparency a pro-ethical condition.

A large portion of the interviews were dedicated to either explicitly or implicitly talking about the role of terms and conditions and how to present them (or not) in ways that increase consumers' understanding. In the Making information understandable section, C2R1 says that consumers "can't see the forest for the trees" when 
they are given all the information insurance companies present to them (by law as well as by choice) when signing an insurance policy. Conditions, in the way they are currently structured, are described in interviews both as examples of a current lack of transparency and as limiting what transparency might accomplish. To alleviate this and create the "best insurance experience" (C1R1), several respondents talk about writing terms and conditions in a more accessible language, or having another set of explanations altogether, with the terms and conditions only serving as further (legally binding) reading.

A specific aspect of expectation management is that of being transparent with the process of insurance. In other words, not (complicated) data or algorithms but (simpler) openness when it comes to where in the process the customer is, be it while signing up for insurance, having filed a claim or just knowing your place in line when speaking to customer support. C1R2 talks about removing the waiting-in-linepart of customer service altogether as a way to increase accessibility and therefore transparency. Whether increasing transparency in the process might help in increasing trust has not been verified in the literature, but there is ample evidence in the HCI field that waiting time is a source of frustration (e.g. Lallemand and Gronier 2012).

\section{Pricing information}

Price is another point of contention. It is the aspect most frequently mentioned as something that should limit transparency. Yet, respondents argue that price is both something that should be transparent and should not be transparent-it is a fairly basic piece of information as well as an extremely complicated process. These contrasts seem to depend on specific lines of insurance. If a health insurance quote for a company is given simply based on the average age of the employees, the information is simple and there is hardly any need to not be transparent with what goes on. If an individual is given a quote based on 26 parameters interacting, there is less inherent transparency in pricing and this will increase the need to explain to the individual what has happened in order to maintain trust (Kizilcec 2016).

As mentioned in the interviews, price, or at least price in relation to coverage, might be the most central deciding factor for individuals when choosing insurance. If this is the case, then it makes some sense to keep information from competitors (as exemplified by C2R3 who argues against open quotes online as it can lead to customers 'hacking' the price), but at the same time it makes little sense to not show consumers the actual value of the product. Some discussed transparency similarly to Lynch (2009), arguing that showing how revenue schemes work is a part of trust building.

Some of the respondents also foresaw a future where pricing might become more intricate due to the use of more advanced technologies looking at the data sets available, and more data sets becoming accessible for industry actors, eventually leading to companies being able to set fully individual premiums. While C2R3 describes this development as a force of nature and that it might lead to a scenario where only the people who have risks will pay for insurance, C4R1 argues vehemently that such 
a development would undermine the entire idea of insurance. If premiums are fully individual it means that each individual carries their own risk in its entirety, therefore making insurance redundant (except as a risk assessment service).

\section{Demands on operations}

In the interviews, several demands on the operations of the company were mentioned. Both $\mathrm{B} 2 \mathrm{~B}$ and $\mathrm{B} 2 \mathrm{C}$ contacts require transparency, but in $\mathrm{B} 2 \mathrm{~B}$ it is a hygiene factor-if there is no transparency there will be no business relationship. The argument is specifically relevant for larger business contracts, where the buyer has an incentive to vet the offer more fully than a smaller actor can, possibly through brokers. In such relationships there is simply no alternative in which the insurance company does not motivate or reveal the background information to any changes proposed to premiums or terms and conditions. In B2C, a few respondents note that consumers do demand transparency, and that there might be increasing demand in the future. C3R2 twice mentions that transparency in operations is requested only when customers feel they have gotten the wrong decision, as was described by Kizilcec (2016). However, most respondents also questioned the ability to comprehend the terms and conditions, which, motivated or not, was not a concern when it came to $\mathrm{B} 2 \mathrm{~B}$ relations.

There are, however, demands on the B2C side on accessibility to customer service, as well as evolving attitudes towards surveillance and use of data. As mentioned in the Data on consumer attitudes section, there is general skepticism towards the increased use of data, but we also see resignation from consumers when choosing between other values, such as price and transparency. Respondents also discussed the demands on the company of fulfilling the obligations in the terms and conditions. A complicating factor that was mentioned by C3R2 in The value of transparency section was that transparency might, paradoxically, lead to decreased understandability. The reasoning here is that if the terms and conditions, or pricing models, are based on a large number of factors, being open with all of this without making an effort to present it intelligibly would make both the customer service employee and the customer feel confused and overwhelmed, rather than feeling like they understand what is going on-despite being presented with a 'full' picture.

\section{Relationship with competitors}

In conjunction with pricing information, respondents talked about the relationship with competitors and how transparent a company can be in a highly competitive market such as insurance. As stated in Pricing information, overly transparent pricing information might disclose vital information to competitors. Several respondents seem to indicate that this is the risk that the companies have identified and deemed most relevant when it comes to how to display pricing - the risk of disclosing information to competitors, rather than being transparent with consumers. 'Business secrets' was a commonly mentioned limitation to transparency in the interviews. Again, this can be contrasted with 
statements on the fact that some insurance is so simple that transparency should not be an issue.

When it came to the openness of terms and conditions on websites, on which C3R2 mentioned developing their own terms and conditions based on those of competitors. What is covered by insurance is a reasonably good indicator of how high the value of the insurance is, but this aspect of transparency did not come up in any other interview.

There is also the view that transparency can be used to disrupt the market (citing customer demand for transparency as the mechanism), or at least gain market share from competitors. There are actors that claim that they are better than their competitors, and some that even advertise it. This mechanism gets some support by Delade Meningar (2019). There are, however, several statements from other respondents arguing against this being a determining factor in choosing an insurance provider. Both statements could be true simultaneously - transparency might not be a determining factor in general, but Bhaduri and Ha-Brookshire (2011) and Cambier and Poncin (2020) show that for certain groups it may be a lot more important and effective.

\section{Relationship with the individual}

Aside from making insurance understandable and trying to build trust, there are several other interactions that the insurance company has with its customers or other individuals. Making customers take better decisions is a more frequent part of the work of the insurance market, as a way to mitigate risks rather than pricing out customers with higher risk.

The use of personal data, and the reasons for using that data, are of course closely related to the functioning of the insurance, but can also serve as a relationship in itself due to legal frameworks such as the GDPR. Additionally, several respondents seemed to confirm the results from Delade Meningar (2018, 2019) and Morey et al. (2015) that consumers may feel uneasy about the increased use of personal data and surveillancelike methods. C3R2 described a scenario where most consumers seem to like the idea of smart car insurance, where insurance companies use telematics to monitor driving behaviour and encourage safer driving. Most consumers also seem to understand the need, but when the consumer actually gets to choose, very few choose the smart insurance. According to C3R2 this is because of the feeling of being surveilled. However, there are other possible explanations, such as people ultimately not wanting to be compared to other drivers and having themselves exposed as less safe than they assume themselves to be. This is somewhat strengthened by C4R1, who argues that most of the people who complain about pricing rarely do it simply because they think it is expensive, but rather that they consider themselves a better risk than the price indicates.

\section{Al and future-proofing}

Finally, when considering the future of insurance in the face of the rising use of machine learning and AI, respondents highlighted the black box problem of such technologies. It creates both an internal problem of explanation as well as an 
external one when consumers ask for the reason for a negative decision ("We can't explain anything, we can only see that it is correct", says C3R2).

When faced with the question of using more advanced technologies (than are currently being used) most respondents stopped at saying they did not feel confident in discussing the technologies since they did not know enough about it. Since these are experts and managers within product development and customer service/experience, this is noteworthy. Most of these experts are not acquainted enough with AI solutions to judge their application in insurance, which means that either the technology is currently very far from being adopted in the industry, or the people who work in specific types of insurance are not involved in the process of developing AI solutions, with the former being the more probable answer.

Some, however, did feel more confident discussing such applications. In those cases, the discussions all ended up focusing on the balance between effective decision-making capabilities and the need or want to be transparent with the workings of the insurance. In one case, the respondent said that the foremost principle ought to be that the company should only use AI technologies that are explainable, thereby sacrificing efficiency. A moment later, the respondent instead said that it will depend on how intrusive the technology is, opting instead to say that efficiency can sometimes be more important. This somewhat contradictory statement is as good an indication as any about the current state of thinking about these issues.

\section{Validity and reliability}

To answer the research questions there are some issues that need to be clarified. Firstly, the matter of selection of the experts. In recruiting experts for the interview studies, the authors contacted all of the major insurance providers in Sweden, as well as some smaller ones. We were aware that the topic might be somewhat sensitive. As it turned out, three out of the four companies that are represented in the study are mutually owned companies, either wholly or with a controlling share. That insurance is a 'business of trust' is not limited to mutually owned companies, and we have no reason to expect that our results are only valid for a specific ownership structure, but cannot rule out that the results may have differed with a fuller representation of the Swedish insurance market.

There is also the issue of how the interviews were conducted. Five interviews were conducted during the fall of 2019, while three were conducted during the spring of 2020. Due to the outbreak of COVID-19, the three latter interviews were all conducted digitally. While the expertise of the interviewee is not in question, and the interviewers had built up more expertise during the course of interviewing, it is harder to establish the same rapport in online interviews as in physical ones.

For both the questionnaire and parts of the interview there is a framing problem. Transparency is mostly seen as a positive thing. Because of this, a gut reaction will be to answer in the affirmative when asked straightforward questions about the benefit of transparency. Because of this, we have chosen not to use some of the initial responses given at face value, but based our data results on the in depth arguments 
that came later in the interview. The respondents, being professionals in the field, showed a lot more depth and nuance than the initial $\mathrm{Y} / \mathrm{N}$ question gives credit for.

Despite the questionnaire reaching a non-negligible population of insurance industry professionals, it only covers employees at a single company, and we have no information about the distribution of knowledge, demographics or roles. The initial idea was that respondents would expand on their answer to the yes/no question in a free text format, but since none of the respondents chose to use this option, we have no deeper understanding of what type of reasoning they employed to arrive at their answers. That being said, the answers to the questionnaire support the findings in Delade Meningar (2019) and give a good indication of what insurance professionals might think about the overarching problem.

As for the research questions, the above sets the framework for how to look at the answers to RQ1. RQ2 shares a similar framework, but without any emphasis on the questionnaire. RQ3 \& RQ4 are narrower in focus and, as such, the respondents are well suited to answer the questions with high validity and reliability, aside from the problem of selection.

A final note about the respondents is that they do not, yet, use AI to its full potential. This limits the possibility of making too far-reaching inferences about the impact of AI and transparency in the industry based on the interviews.

\section{Conclusions and future work}

Transparency is a broad topic. In this article, a plethora of perspectives on transparency have been presented.

With respect to RQ1, there is widespread belief, among interviewees as well as questionnaire respondents, that transparency could be a competitive advantage, but when asked to delve deeper on the topic respondents show no consensus on precise mechanisms and circumstances by which to do so. The potential benefits showed by Kang and Hustvedt (2014), Bhaduri and Ha-Brookshire (2011) and Cambier and Poncin (2020) might hold true for insurance as well but, despite enthusiasm, respondents are uncertain about how to make it happen in practice.

Similarly, with respect to RQ2, the majority of the companies represented do not use transparency in a strategic manner to gain competitive advantage. $\mathrm{C} 1$ does try, and C4 claims they are currently the best in the business. The overarching impression is that while the insurance industry considers itself in 'the business of trust', there is no distinct plan for how to use transparency to enhance that trust-despite all respondents believing that there is an advantage that could be realised. That is, insurance companies fail to utilise transparency as a pro-ethical condition (Turilli and Floridi 2009).

However, all companies interviewed see improvements that could be made. All respondents noted areas where they are not only not transparent today, but where they consider themselves lacking. The potential of using transparency to set proper expectations on the insurance product is one of the striking similarities between the respondents, as well as the need to increase understandability in order to set proper 
expectations, even if this seems to be a potential value rather than a currently realised one.

With respect to RQ3, limitations to transparency identified by the respondents include (i) legal requirements (important), (ii) the problem of making the information that could be transparent understandable (iii) and the risk of disclosing models to competitors and customers. Respondents, while agreeing that understandability is a problem, do not seem to agree on what information ought to be made understandable, or how understandability could be improved. This leaves room for future research.

With respect to RQ4, it is apparent that $\mathrm{AI}$ is not used in the core of the insurance industry in Sweden (though the use of AI for specific tasks such as chat bots exists both as trials and in live adaptations). With increased adoption of AI technology, the issues of (i) unease (with too granular models) and (ii) fundamental limitations on explainable AI are expected to create further limits on transparency.

However, several respondents pointed to the question of transparency and AI currently being of theoretical rather than practical interest, as the companies are far from implementing any such technology.

Throughout the interviews, a common theme has been the ability to gain, and requirements of sustaining, trust from consumers through transparency. Respondents point to the setting of expectations through the use of more understandable policies, where correctly set expectations could increase consumer trust. The institutional trust in insurance companies might limit the need for consumers to actually understand what the insurance contains, an aspect where transparency might both undermine current expectations and build better future expectations. There is discussion on the ability (or inability) of transparency to quell mistrust in pricing that seems disadvantageous, and a hypothetical discussion on whether either insurance companies or consumers can trust black box decisions from artificial intelligence, and whether that is an acceptable route to take in 'the business of trust'.

In summary, the article shows a belief that transparency could offer a competitive advantage for the insurance industry, but there is disagreement as to the extent of that advantage and of the ways to realise it. Findings include no evidence of strategic use of transparency in the industry, even though the interviews pointed at areas that could be improved. The respondents see several limitations to transparency, and most respondents are uncertain of future demands, as the industry is not as close to using artificial intelligence as initially assumed.

\section{Future work}

Based on this article, and the issues identified, there are many opportunities for future work. Notably, performing similar studies in the insurance industry in other countries, as well as in other industries altogether, might shed more light on how the dilemmas of transparency, trust and AI adoption look in these contexts.

As few of the respondents in the interviews felt comfortable talking about the implications of AI on transparency, further research ought to be done on what kind 
of transparency would be possible and necessary for insurance companies in the near future.

Another avenue would be case studies of AI- and/or transparency-driven start-ups and other market innovators to explore the potential of actually using transparency in a market where it is, probably, not currently used to its full potential.

To further enrich and contextualise the results reported, it would also be interesting to conduct further interviews with people from different parts of the companies, for instance with customer service employees and those at the strategic level, as well as with IT departments. More in-depth interview studies could also be performed within particular lines of insurance, such as health or motor insurance.

\section{References}

Abdul, A., J. Vermeulen, D. Wang, B.Y. Lim, and M. Kankanhalli. 2018. Trends and trajectories for explainable, accountable and intelligible systems: an HCI research agenda. In Proceedings of the $2018 \mathrm{CHI}$ conference on human factors in computing systems, 1-18. DOI: https://doi. org/10.1145/3173574.3174156

Adams, J.E., S. Highhouse, and M.J. Zickar. 2010. Understanding general distrust of corporations. Corporate Reputation Review 13 (1): 38. https://doi.org/10.1057/crr.2010.6

Adebayo, J., J. Gilmer, M. Muelly, I. Goodfellow, M. Hardt, and B. Kim. 2018. Sanity checks for saliency maps. In Advances in neural information processing systems, 9505-9515.

Andrews, R., J. Diederich, and A.B. Tickle. 1995. Survey and critique of techniques for extracting rules from trained artificial neural networks. Knowledge-Based Systems 8 (6): 373-389.

Atchinson, B.K. 2004. Walking the talk: Ethics as corporate culture. The Geneva Papers on Risk and Insurance-Issues and Practice 29 (1): 40-44.

Barakat, N., and A.P. Bradley. 2010. Rule extraction from support vector machines: A review. Neurocomputing 74 (1-3): 178-190.

Bhaduri, G., and J.E. Ha-Brookshire. 2011. Do transparent business practices pay? Exploration of transparency and consumer purchase intention. Clothing and Textiles Research Journal 29 (2): 135-149.

Bushman, R., and W.R. Landsman. 2010. The pros and cons of regulating corporate reporting: A critical review of the arguments. Accounting and Business Research 40 (3): 259-273. https://doi. org/10.1080/00014788.2010.9663400.

Cambier, F., and I. Poncin. 2020. Inferring brand integrity from marketing communications: The effects of brand transparency signals in a consumer empowerment context. Journal of Business Research 109: 260-270. https://doi.org/10.1016/j.jbusres.2019.11.060.

Castelvecchi, D. 2016. Can we open the black box of ai? Nature News 538 (7623): 20. https://doi. org/10.1038/538020a.

Coeckelbergh, M. 2019. Artificial intelligence, responsibility attribution, and a relational justification of explainability. Science and Engineering Ethics 26: 2051-2068. https://doi.org/10.1007/s11948-01900146-8.

Cucciniello, M., G.A. Porumbescu, and S. Grimmelikhuijsen. 2017. 25 years of transparency research: Evidence and future directions. Public Administration Review 77 (1): 32-44. https://doi. org/10.1111/puar.12685.

Cupach, W.R., and J.M. Carson. 2002. The influence of compensation on product recommendations made by insurance agents. Journal of Business Ethics 40 (2): 167-176. https://doi.org/10.1023/A:10203 55118527.

de Castries, H. 2004. Ethics, governance, trust, transparency and customer relations. The Geneva Papers on Risk and Insurance-Issues and Practice 29 (1): 36-39.

de Laat, P.B. 2018. Algorithmic decision-making based on machine learning from big data: Can transparency restore accountability? Philosophy \& Technology 31 (4): 525-541.

Delade Meningar. 2018. Delade meningar 2018 [Shared opinions 2018]. Tech. rep., Insight Intelligence. https://www.insightintelligence.se/delade-meningar/delade-meningar-2018 
Delade Meningar. 2019. Delade meningar 2019 [Shared opinions 2019]. Tech. rep., Insight Intelligence. https://www.insightintelligence.se/delade-meningar/delade-meningar-2019

Dennett, D.C. 1989. The intentional stance. New York: MIT press.

Dexe, J., J. Ledendal, and U. Franke. 2020. An empirical investigation of the right to explanation under GDPR in insurance. In Trust, privacy and security in digital business, 125-139. Cham: Springer International Publishing. DOI: https://doi.org/10.1007/978-3-030-58986-8 9

Dickinson, G., and P.M. Liedtke. 2004. Impact of a fair value financial reporting system on insurance companies: A survey. The Geneva Papers on Risk and Insurance-Issues and Practice 29 (3): 540581. https://doi.org/10.1111/j.1468-0440.2004.00302.x.

Du, M., N. Liu, and X. Hu. 2019. Techniques for interpretable machine learning. Communications of the ACM 63 (1): 68-77. https://doi.org/10.1145/3359786.

The Economist. 2017. The future of insurance: Counsel of protection. 67-68.

Fleischmann, K.R., and W.A. Wallace. 2005. A covenant with transparency: Opening the black box of models. Communications of the ACM 48 (5): 93-97.

Focht, U., A. Richter, and J. Schiller. 2013. Intermediation and (mis-)matching in insurance marketswho should pay the insurance broker? Journal of Risk and Insurance 80 (2): 329-350. https://doi. org/10.1111/j.1539-6975,2012.01475.x.

Guidotti, R., A. Monreale, S. Ruggieri, F. Turini, F. Giannotti, and D. Pedreschi. 2018. A survey of methods for explaining black box models. ACM Computing Surveys (CSUR) 51 (5): 1-42. https://doi. org/10.1145/3236009.

Insurance Sweden. 2016. Omvärldstrender 2017 - utmaningar och möjligheter för försäkringsbranschen [Global trends 2017 - challenges and opportunities for insurance]. https://www.svenskforsakrin g.se/globalassets/rapporter/omvarldsbeskrivning/sf_omvarld_2017.pdf

Kang, J., and G. Hustvedt. 2014. Building trust between consumers and corporations: The role of consumer perceptions of transparency and social responsibility. Journal of Business Ethics 125 (2): 253-265.

Kim, S., and J. Lee. 2012. E-participation, transparency, and trust in local government. Public Administration Review 72 (6): 819-828.

Kim, S.B., and D.Y. Kim. 2017. Antecedents of corporate reputation in the hotel industry: The moderating role of transparency. Sustainability 9 (6): 951. https://doi.org/10.3390/su9060951.

Kizilcec, R.F. 2016. How much information? Effects of transparency on trust in an algorithmic interface. In Proceedings of the 2016 CHI Conference on Human Factors in Computing Systems, 2390-2395. https://doi.org/10.1145/2858036.2858402

Klingler, D. 2018. Insurtech: Refreshingly different-like lemonade! The InsurTech book: The insurance technology handbook for investors, entrepreneurs and FinTech visionaries, pp. 157-160.

Köhne, T., and C. Brömmelmeyer. 2018. The new insurance distribution regulation in theEU-a critical assessment from a legal and economic perspective. The Geneva Papers on Risk and InsuranceIssues and Practice 43 (4): 704-739. https://doi.org/10.1057/s41288-018-0089-0.

Kugler, L. 2018. The war over the value of personal data. Communications of the ACM 61 (2): 17-19. https://doi.org/10.1145/3171580.

Lakkaraju, H., and O. Bastani. 2020. "How do I fool you?" Manipulating user trust via misleading black box explanations. In Proceedings of the AAAI/ACM conference on AI, Ethics, and Society, 79-85. https://doi.org/10.1145/3375627.3375833

Lallemand, C., and G. Gronier. 2012. Enhancing user experience during waiting time in HCI: contributions of cognitive psychology. In Proceedings of the designing interactive systems conference, association for computing machinery, New York, NY, USA, DIS '12, 751-760. https://doi. org/10.1145/2317956.2318069

Lynch, J. 2009. Financial service professionals earn their compensation. Journal of Financial Service Professionals 63 (4): 27.

Malinowska, K. 2016. Insurance transparency and protection regime under the insurance distribution directive. Wiadomo'sci Ubezpieczeniowe Insurance Review 4: 89-101.

Morey, T., T. Forbath, and A. Schoop. 2015. Customer data: Designing for transparency and trust. Harvard Business Review 93 (5): 96-105.

Nature. 2016. More accountability for big-data algorithms. Nature 537 (7621): 449. https://doi. org/10.1038/537449a.

O'Neil, C. 2016. No safe zone - getting insurance. In Weapons of math destruction: how big data increases inequality and threatens democracy, 161-178. Broadway Books. 
Park, H., and J. Blenkinsopp. 2011. The roles of transparency and trust in the relationship between corruption and citizen satisfaction. International Review of Administrative Sciences 77 (2): 254-274.

Riikkinen, M., H. Saarijärvi, P. Sarlin, and I. Lähteenmäki. 2018. Using artificial intelligence to create value in insurance. International Journal of Bank Marketing 36 (6): 1145-1168.

Rossi, F. 2018. Building trust in artificial intelligence. Journal of International Affairs 72 (1): 127-134. https://doi.org/10.2307/26588348.

Samek, W., A. Binder, G. Montavon, S. Lapuschkin, and K.R. Müller. 2016. Evaluating the visualization of what a deep neural network has learned. IEEE Transactions on Neural Networks and Learning Systems 28 (11): 2660-2673.

Scott, J. 2004. Ethics, governance, trust, transparency and customer relations. The Geneva Papers on Risk and Insurance-Issues and Practice 29 (1): 45-51.

Siau, K., and W. Wang. 2018. Building trust in artificial intelligence, machine learning, and robotics. Cutter Business Technology Journal 31: 47-53.

Spiekermann, S., and J. Korunovska. 2017. Towards a value theory for personal data. Journal of Information Technology 32 (1): 62-84. https://doi.org/10.1057/jit.2016.4.

Turilli, M., and L. Floridi. 2009. The ethics of information transparency. Ethics and Information Technology 11 (2): 105-112.

van Rossum, A. 2004. Ethics, governance, trust and customer relations. The Geneva Papers on Risk and Insurance-Issues and Practice 29 (1): 52-55. https://doi.org/10.1111/j.1468-0440.2004.00268.x.

van der Sluijs, J. 2019. Transparency in the insurance contract law of Sweden. In Transparency in insurance contract law, ed. P. Marano, 257-277 Springer. https://doi.org/10.1007/978-3-030-31198-8 10

Winfield, A.F., and M. Jirotka. 2018. Ethical governance is essential to building trust in robotics and artificial intelligence systems. Philosophical Transactions of the Royal Society A Mathematical, Physical and Engineering Sciences 376 (2133): 20180085. https://doi.org/10.1098/rsta.2018.0085.

Wischmeyer, T. 2020. Artificial intelligence and transparency: Opening the black box. In Regulating artificial intelligence, 75-101. Springer. https://doi.org/10.1007/978-3-030-32361-5 4

Zboron, M. 2015. Insurance underwriting and broking in the London insurance market: The role of reputation and trust in the insurance decision making process. PhD thesis, University of Southampton.

Zerilli, J., A. Knott, J. Maclaurin, and C. Gavaghan. 2019. Transparency in algorithmic and human decision-making: Is there a double standard? Philosophy \& Technology 32 (4): 661-683.

Publisher's Note Springer Nature remains neutral with regard to jurisdictional claims in published maps and institutional affiliations.

\section{About the authors}

Jacob Dexe is a researcher at Research Institutes of Sweden (RISE) and a PhD student at the KTH School of Electrical Engineering and Computer Science. His research is in transparency in algorithmic decision-making.

Dr. Ulrik Franke is a senior researcher at RISE and an affiliated faculty member at the KTH School of Electrical Engineering and Computer Science. His research interests include transparent algorithms, cyber situational awareness, cyber insurance, IT service availability and enterprise architecture.

Dr. Alexander Rad is a senior researcher at RISE and his research covers the financial services industry, governance and risk management. 